Article

\title{
Behavior of gold nanoparticles in a titania aerogel matrix: Photocatalytic activity assessment and structure investigations
}

\author{
Zsolt PAP a , Andreea RADU ${ }^{\text {b }}$, Izabella Jolan HIDI ${ }^{\text {b }}$, Georgian MELINTE b , Lucian DIAMANDESCU ${ }^{c}$, \\ Traian POPESCU c, Lucian BAIA ${ }^{\text {b,d }}$, Virginia DANCIU a, Monica BAIA ${ }^{\text {b,d,* }}$ \\ a Faculty of Chemistry and Chemical Engineering, Babes-Bolyai University, 11 Arany Janos str., 400028, Cluj-Napoca, Romania \\ ${ }^{\mathrm{b}}$ Faculty of Physics, Babes-Bolyai University, 1 Mihail Kogalniceanu str., 400084, Cluj-Napoca, Romania \\ ${ }^{c}$ National Institute of Materials Physics, P. O. Box MG-7, 77125, Bucharest-Magurele, Romania \\ d Institute for Interdisciplinary Research in Bio-Nano-Sciences, Babes-Bolyai University, 42 Treboniu Laurian str., 400271, Cluj-Napoca, Romania
}

\section{A R T I C L E I N F O}

\section{Article history:}

Received 15 October 2012

Accepted 26 November 2012

Published 20 April 2013

\section{Keywords:}

Nanomaterial

Sol-gel

Titania

Salicylic acid

Photocatalytic performance

\begin{abstract}
A B S T R A C T
$\mathrm{TiO}_{2}$-Au aerogels containing different amounts of gold nanoparticles of different sizes ( 5 and $16 \mathrm{~nm}$ ) were successfully synthesized using a sol-gel procedure, and were tested for salicylic acid photodegradation under UV irradiation. The structure and morphology of the obtained materials were investigated using X-ray diffraction, transmission electron microscopy, and $\mathrm{N}_{2}$ adsorption-desorption measurements. UV-Vis spectroscopy was used to study the optical properties. The effects of the gold nanoparticles on the $\mathrm{TiO}_{2}$ crystallization process were twofold, as follows: (i) the number of crystallized zones was strongly related to the concentration of the gold nanoparticles, and (ii) the smaller gold particles increased the time taken for the crystallization of the samples. It was found that the noble metal-doped samples exhibited higher degradation rates compared with bare titania. It was found that the most active photocatalyst in each studied system was the sample with the highest concentration of gold nanoparticles. Additionally, the highest degradation rate value was obtained with the smallest Au nanoparticles $\left(46.4 \times 10^{-3} \mu \mathrm{mol} /(\mathrm{L} \cdot \mathrm{s})\right.$.
\end{abstract}

(C) 2013, Dalian Institute of Chemical Physics, Chinese Academy of Sciences. Published by Elsevier B.V. All rights reserved.

\section{Introduction}

In recent decades, much progress has been made in attempts to achieve the depollution of soil, water, and air [1-5]. The detection of pollutants has been performed by pre-extracting large quantities of water and performing chromatographic analysis [1,2]. To clean waters before they are discharged into rivers or sent to be processed for drinking water, adsorption on active carbon, chemical oxidation, or aerobic biological treatments have been applied [3-5]. Nevertheless, pollution remains a serious issue that attracts the scientific world's attention [6-12]. With an increasing number of publi- cations in the field, the degradation of water and air pollutants via heterogeneous photocatalytic processes appears to be a promising solution for this problem [10,12-14]. This is in part because of its simplicity, as it requires only that a photocatalyst is in contact with the medium that contains the pollutant (i.e., liquid, gas). The catalyst is activated via the absorption of photons of appropriate energy. As a consequence, electron $\left(\mathrm{e}^{-}\right)$hole $\left(\mathrm{h}^{+}\right)$pairs are generated, and they migrate to the surface of the photocatalyst. The $\mathrm{e}^{-}$and $\mathrm{h}^{+}$that do not recombine before reaching the photocatalyst's surface are engaged in different reactions with the surface molecules, resulting in the formation of highly reactive species (i.e., $\mathrm{OH}$ radicals) [15], which are

*Corresponding author. Tel: +4-264-405300; Fax: +4-264-591906; E-mail: monica.baia@phys.ubbcluj.ro This work was supported by CNCSIS-UEFISCSU (PN II-RU_TE 81/2010). 
subsequently responsible for the pollutants' decomposition into less harmful components $[15,16]$.

Titanium dioxide is among the most studied semiconductors for the processes described above, because of its high photosensitivity, low toxicity, and stability. In addition, loading titanium dioxide with gold nanoparticles increases the photocatalytic efficiency. This is because the contact between $\mathrm{Au}$ and the $\mathrm{TiO}_{2}$ nanoparticles influences the energetic and interfacial charge transfer processes in a favorable way $[17,18]$. As already discussed, when a bare $\mathrm{TiO}_{2}$ semiconductor is irradiated with UV light, electron-hole pairs are created. However, because of the small lifetime of these charge carriers (the approximate lifetime of a generated electron is $30 \mathrm{ps}$, while that of a hole is of 250 ns [19-21]), they do not always reach the surface to start the reactions that are responsible for the pollutant's photodegradation. The presence of $\mathrm{Au}$ nanoparticles helps to avoid this drawback, because the combination of the gold with the titania matrix results in the formation of an efficient electron trap (Schottky junction), and improves the photocatalyst's response to illumination [18,22-24]. More precisely, under UV irradiation, the electronic charge transfer takes place from the excited $\mathrm{TiO}_{2}$ into the $\mathrm{Au}$, while the barrier formed hinders the inverse charge transition [18,25,26].

The benefit conferred by the addition of the gold nanoparticles to the titania matrix can be further enhanced if the dispersed phase (i.e., the gold nanoparticles) are embedded in a porous $\mathrm{TiO}_{2}$ structure. Titania aerogels are realistic candidates for this task, because aerogels are porous solid materials with high surface area, ultra-low density, and high homogeneity [27-29]. Furthermore, the aggregation of the metal nanoparticles can be avoided; the diffusion of analytes (i.e., the pollutant) is enhanced, and the number of metal/analyte contacts is increased [30]. The positive effects of the gold nanoparticles on the charge separation efficiency is also exploited in the photocatalytic hydrogen generation, where the "lured" electron is used for hydrogen reduction (at the Au nanoparticle's surface), while the hole is used for the degradation of the surface-adsorbed pollutant [31,32].

In a previous study, we prepared $\mathrm{TiO}_{2}-\mathrm{Au}$ nanocomposites by impregnating $\mathrm{TiO}_{2}$ gels with different amounts of Au nanoparticles of given dimensions, followed by supercritical drying. Their photocatalytic activity was subsequently evaluated using UV-Vis irradiation [33]. Considering the promising nature of the results, we propose to obtain a deeper understanding of the role played by the dimension and concentration of the Au nanoparticles located inside the $\mathrm{TiO}_{2}$ porous network in deciding the material's photocatalytic properties when UV light is used for irradiation. Thus, in this work, porous nanoarchitectures based on $\mathrm{TiO}_{2}$ aerogels and Au colloidal particles of two different dimensions were obtained.

To achieve the proposed aim, the prepared porous composites were structurally investigated using X-ray diffraction (XRD) and UV-Vis spectroscopy, and their morphological particularities were evaluated using $\mathrm{N}_{2}$ adsorption-desorption measurements and transmission electron microscopy (TEM). The photocatalytic activity data were further correlated with those derived from the morpho-structural analysis.

\section{Experimental}

\subsection{Sample preparation}

\subsubsection{Preparation of gold nanoparticles}

The 16-20 nm gold colloidal suspension was obtained using a slightly modified Turkevich's procedure [34]: $25 \mathrm{mmol} / \mathrm{L}$ $\mathrm{HAuCl}_{4} \cdot 3 \mathrm{H}_{2} \mathrm{O}(50 \mathrm{~mL})$ was brought to the boil under vigorous stirring. $1 \% \mathrm{Na}_{3} \mathrm{C}_{3} \mathrm{H}_{5} \mathrm{O}(\mathrm{COO})_{3}(2 \mathrm{~mL})$ was added to the solution all at once under vigorous stirring. Stirring and boiling was continued for $10 \mathrm{~min}$. The solution was then removed from the heat and stirring was continued until the solution had cooled.

The 4-7 nm gold nanoparticles were prepared according to the Brust et al. method [35], adapted as follows: $42 \mathrm{~mL}$ of 20 mmol/L $\mathrm{NaBH}_{4}$ was added to a $350 \mathrm{~mL}$ of $0.5 \mathrm{mmol} / \mathrm{L} \mathrm{HAuCl}_{4}$ solution. The reaction took place in an ice bath under vigorous stirring.

\subsubsection{Preparation of $\mathrm{Au} / \mathrm{TiO}_{2}$ aerogels}

$\mathrm{TiO}_{2}$ gels were prepared using the one-step sol-gel procedure, using $\mathrm{Ti}_{4}\left(\mathrm{OCH}_{3}\right)_{16}, \mathrm{HNO}_{3}, \mathrm{C}_{2} \mathrm{H}_{5} \mathrm{OH}(\mathrm{EtOH})$, and $\mathrm{H}_{2} \mathrm{O}$ at molar ratios of 1:0.08:21:3.675 [6]. The gels were aged for 3 weeks, and then immersed in different amounts of the Au colloidal solutions $(50,200$, and $300 \mathrm{~mL})$ for $3 \mathrm{~d}(16-20 \mathrm{~nm} \mathrm{Au}$ nanoparticles), and $1 \mathrm{~d}$ (7-10 nm Au nanoparticles), respectively. Afterwards, they were washed with an excess of fresh EtOH. In the next step, the obtained gels were dried under supercritical conditions, using liquid $\mathrm{CO}_{2}(T=313 \mathrm{~K}$ and $p=95.23$ atm) with a homemade supercritical drying device.

The samples were coded as follows: S-G (number) - (number) $\times$ (e.g., S-G5-1×); where "S" represents the sample; "G" gold; the number after $G$ gives the gold nanoparticles' average size in $\mathrm{nm}$, and the last term (number) $\times$ gives the quantity of gold suspension used in the impregnation process (i.e., $1 \times$ means base quantity (50 mL), and $4 \times$ means a fourfold quantity).

\subsection{Methods and instrumentation}

\subsubsection{Gold nanoparticle size estimations}

To confirm the proposed dimensions of the gold nanoparticles, the UV-Vis absorption spectra of the colloidal suspension were recorded using a JASCO V-650 UV-Vis spectrophotometer. After the synthesis of the as-prepared samples, the amount of gold present in the catalysts was estimated using energy dispersive X-ray analysis (EDX). Elemental mapping was performed using a JEOL JSM 5510LV scanning electron microscope. The $\mathrm{Au}$ amounts given here represent the average values calculated from measurements performed on four areas of the same sample. One should note that the difference between the recorded and the average values was smaller than $6 \%$.

\subsubsection{Crystal phase composition, particle size/morphology}

To obtain information on the crystallinity characteristics of the resulting materials, they were analyzed using XRD with a Bruker D8 Advance diffractometer ( $\mathrm{Cu} K_{\alpha}$ radiation, $\lambda=$ $0.15406 \mathrm{~nm}$ ). The crystallite's dimensions were calculated by 
applying the Rietveld method [36]. These values were further confirmed by TEM images.

TEM studies revealed the morphology of the samples, and the presence and distribution of the gold nanoparticles. TEM micrographs were recorded on a JEOL JEM 1010 TEM operating at an accelerating voltage of $100 \mathrm{kV}$ and equipped with a MegaViewIII CCD camera.

The surface area and the pore size distribution of the synthesized samples were determined using $\mathrm{N}_{2}$ adsorption-desorption measurements performed on a Sorptomatic 1990 instrument. The surface area was calculated using the Brunauer-Emmett-Teller (BET) three-parameter method.

\subsubsection{Determination of the band-gap energies}

The band-gap energy of the composites was calculated from their diffuse reflectance spectra (not shown), which were recorded using a Jasco V650 diode-array spectrophotometer in the wavelength range of 200-800 $\mathrm{nm}$. Reflectance data were converted to $F(\mathrm{R})$ values using the Kubelka-Munk theory $[37,38]$. The band gap was obtained from the plot of $[F(\mathrm{R}) \cdot E]^{1 / 2}$ versus energy of the exciting light $(E)$, assuming that the investigated porous samples were indirect band-gap crystalline semiconductors.

\subsection{Assessment of the photocatalytic activity}

The photocatalytic activity of the composites was established from the degradation rate of salicylic acid, which is used as a standard pollutant molecule, as reported by Silva et al. [39]. The decrease in the salicylic acid concentration with time $\left(C_{0}=0.5 \mathrm{mmol} / \mathrm{L}\right.$ for all investigated samples) was monitored using a Jasco V-530 UV-Vis spectrophotometer (monitoring the intensity of the band located at $295 \mathrm{~nm}$ ). The composites were immersed in salicylic acid solution and irradiated using six lamps ( $6 \mathrm{~W}$ each, with $\lambda_{\max } \approx 365 \mathrm{~nm}$ ) in a positive irradiation geometry. Before irradiation, the cell with the sample was kept in the dark for 15 min to achieve equilibrium of the adsorption-desorption process. The initial photocatalytic degradation rate $r_{0}$ was used to evaluate the efficiency of the given photocatalyst. The value of $r_{0}$ was evaluated as described in our previous publications [40].

\section{Results and discussion}

\subsection{Characterization results of the $\mathrm{TiO}_{2}-\mathrm{Au}$ nanomaterials}

The UV-Vis absorption spectra for the two mother-colloidal solutions applied in the impregnation process are shown in Fig. 1. The figure revealed two surface plasmon resonances at 510 and $518 \mathrm{~nm}$. The resulting estimated $\mathrm{Au}$ nanoparticle dimensions were approximately 4-7 $\mathrm{nm}$ and $14-18 \mathrm{~nm}$, respectively $[41,42]$.

The obtained $\mathrm{TiO}_{2}$-Au aerogels were investigated using TEM and XRD to identify the crystalline phases, to evaluate the crystallites' size, and to prove the existence of gold nanoparticles on the aerogels' surface. In the S-G5 series, anatase and brookite were found, together with a substantial amount of amorphous

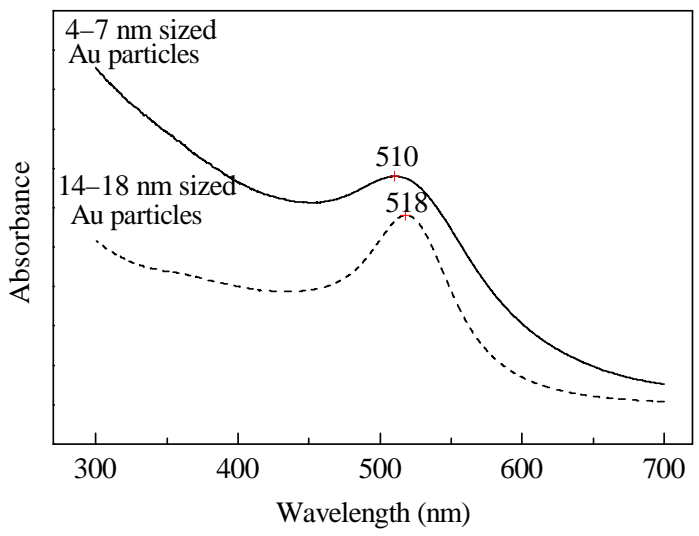

Fig. 1. UV-Vis spectra for the two mother-colloidal solutions applied in the impregnation process.

matter (the XRD patterns are presented in Fig. 2), which is usual for non-thermallytreated aerogels.

The crystallite sizes determined by applying the Rietveld method [36] to these samples were 8-9 $\mathrm{nm}$ for both the anatase and brookite particles (Table 1). These sizes were confirmed by TEM. Aerogels belonging to the S-G16 series reveal diffraction peaks characteristic of the anatase phase only, the estimated mean size of the crystallites being $\approx 7 \mathrm{~nm}$. No traces of gold were detected by XRD, probably because of the very low gold content (see Table 1). However, the presence of the noble metal nanoparticles was confirmed in the TEM micrographs (Fig. 3). The gold nanoparticles' size was estimated to be approximately 4-7 nm (sample series S-G5) and 14-18 nm (sample series S-G16), respectively.

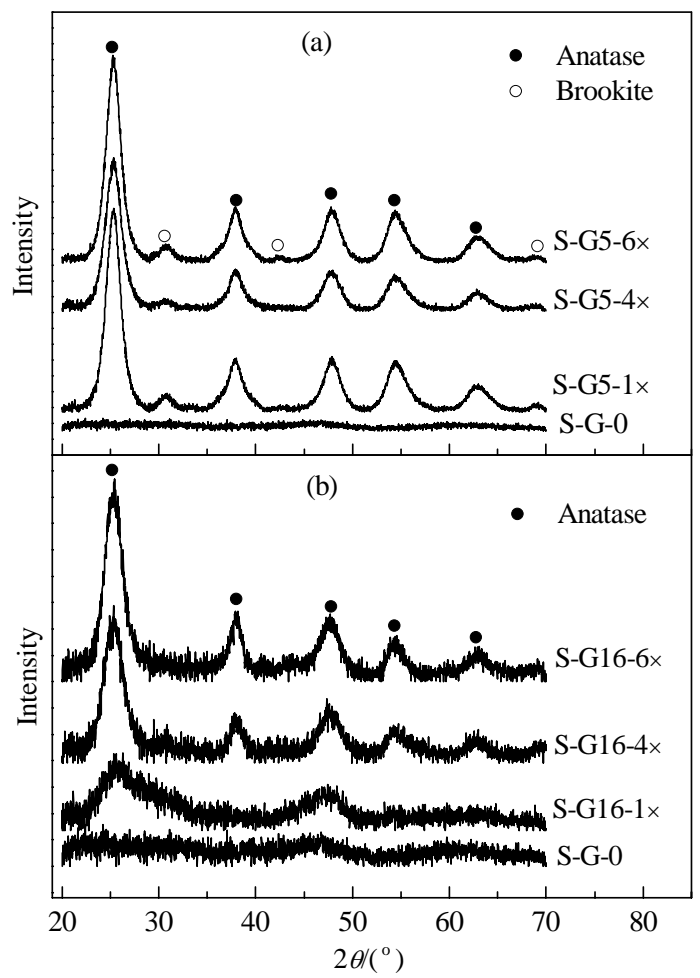

Fig. 2. XRD patterns for the aerogels containing $5 \mathrm{~nm}$ (a) and $16 \mathrm{~nm}$ (b) gold particles. 
Table 1

Structural characteristics and salicylic acid photodegradation rate/efficacy for all of the investigated samples.

\begin{tabular}{|c|c|c|c|c|c|c|c|c|c|c|}
\hline \multirow{2}{*}{ Sample } & \multirow{2}{*}{$\begin{array}{c}\text { Au content } \\
(w t \%)\end{array}$} & \multicolumn{2}{|c|}{ Phase content a (\%) } & \multicolumn{2}{|c|}{ Crystallite size ${ }^{b}(\mathrm{~nm})$} & \multirow{2}{*}{$\begin{array}{c}A_{\mathrm{BET}} / \\
\left(\mathrm{m}^{2} / \mathrm{g}\right)\end{array}$} & \multirow{2}{*}{$\begin{array}{l}\text { Average pore } \\
\text { size }(\mathrm{nm})\end{array}$} & \multirow{2}{*}{$\begin{array}{l}E_{\mathrm{g}} \mathrm{c} / \\
(\mathrm{eV})\end{array}$} & \multirow{2}{*}{$\begin{array}{l}\text { Degradation rate } \mathrm{d} \\
\left(10^{-3} \mu \mathrm{mol} /(\mathrm{L} \cdot \mathrm{s})\right)\end{array}$} & \multirow{2}{*}{$\begin{array}{c}\text { Degradation } \\
\text { efficiency }{ }^{\mathrm{d}}(\%)\end{array}$} \\
\hline & & Anatase & Brookite & Anatase & Brookite & & & & & \\
\hline$S-G-0$ & - & $\mathrm{am}^{\mathrm{e}}$ & $\mathrm{am}$ & am & am & 593 & 11 & 3.17 & - & - \\
\hline S-G5-1× & 0.12 & 72.90 & 27.10 & 8 & 8 & 419 & 5 & 3.18 & 9.1 & 20 \\
\hline S-G5-4x & 0.19 & 83.99 & 16.01 & 9 & 9 & 325 & 4 & 3.15 & 12.6 & 15 \\
\hline S-G5-6x & 0.22 & 100.00 & - & 9 & - & 417 & 4 & 3.15 & 46.4 & 30 \\
\hline S-G16-1× & 0.14 & am & - & - & - & 559 & 9 & 3.28 & 6.5 & 13 \\
\hline S-G16-4× & 0.24 & 100.00 & - & 7 & - & 564 & 14 & 3.28 & 6.5 & 12 \\
\hline S-G16-6x & 0.34 & 100.00 & - & 7 & - & 566 & 9 & 3.22 & 23.2 & 25 \\
\hline P25 & - & 89.00 & 11.00 & 25 & 40 & npg & $\mathrm{np}$ & np & 6.1 & 8 \\
\hline
\end{tabular}

a Given by Rietveld analysis of XRD (error \pm 0.5 ) [36]. ${ }^{b}$ Given by XRD analysis (error \pm 0.6 ). ${ }^{c}$ Absorption band gap from UV-Vis measurements.

${ }^{\mathrm{d}}$ Error \pm 1.0 . ${ }^{\mathrm{e}}$ Amorphous $\mathrm{TiO}_{2}{ }^{\mathrm{f}} 11.00 \%$ rutile. . Non-porous sample.

Considering all of the parameters listed above, it is clear that the gold nanoparticles' presence in the gel system influenced the crystallization pathway of the titania during the supercritical drying process. Accordingly, different crystallinity grades, particle sizes, and crystal phase compositions were obtained. This was further supported by the study of sample S-G0 (the reference sample without any Au nanoparticles). As can be observed from Fig. 2, this sample was highly amorphous, and revealed no defined features that could be associated with the presence of a given crystalline phase. This could mean that the $\mathrm{Au}$ nanoparticles acted as crystallization centers for the $\mathrm{TiO}_{2}$. Direct evidence for this was provided by the presence of different crystalline phases of $\mathrm{TiO}_{2}$ in different proportions in the two sample series. First, in the case of the S-G5 series, both anatase and brookite particles were present. Second, in the S-G16 series, only the anatase phase was observed. Furthermore, the titania grain size was also dependent on the size of the gold nanoparticles. More precisely, while in the sample S-G5 series the anatase particles' mean diameter was 8-9 nm, in the S-G16 series this value was $7 \mathrm{~nm}$ or below (in some cases the crystallinity grade was quite low, and the grain size could not be correctly estimated).

Another consequence of the gold's presence was the decrease in the surface area (see Table 1). Considering that no significant variation in the $\mathrm{TiO}_{2}$ crystallite size was detected as the gold content increased in sample series S-G5, it is not surprising that the surface area values were also similar for all of the studied $\mathrm{Au}$ concentrations. For the aerogels in the S-G16 system, on the other hand, the gold nanoparticles were less homogeneously dispersed (as observed using TEM), which may explain why the surface area values were slightly lower than those of the pure $\mathrm{TiO}_{2}$.

Another important aspect must be considered when discussing this feature, namely the titania matrix's capability to encapsulate the gold nanoparticles. Considering that the BET measurements revealed that the dominating pore size in the pure titania samples was $\approx 11 \mathrm{~nm}$ (see Table 1), we expected that the $5 \mathrm{~nm}$ gold nanoparticles would be uniformly distributed through the matrix. In contrast, the $16 \mathrm{~nm} \mathrm{Au}$ particles were larger than the dominating pore size of the pure titania, and were consequently expected to either agglomerate on the $\mathrm{TiO}_{2}$ surface or, at least, present a less uniform distribution throughout the sample. This was confirmed by a close investigation of the TEM images shown in Fig. 3.

All of the above-mentioned structural modifications were highly dependent on the presence of the gold nanoparticles. This suggested that the sites of the crystallization events were the contact zones between the two materials. The importance of this zone was also observed at Ge-Si contact interfaces [43], where the deposited germanium followed the silicon's crystal lattice in a few atomic layers, adjusting its own crystal system. Lopez and coworkers' [44] theoretical study concerning $\mathrm{Au} / \mathrm{TiO}_{2}$ interfaces also predicts the critical importance of the surface contacts. They concluded that the electronic structure of the supported metals depended significantly on the geometrical situation of the $\mathrm{Au}$ nanoparticles (which in our case varied, because in series S-G16, the Au nanoparticles are mostly localized on the surface of the titania particles, while in the case
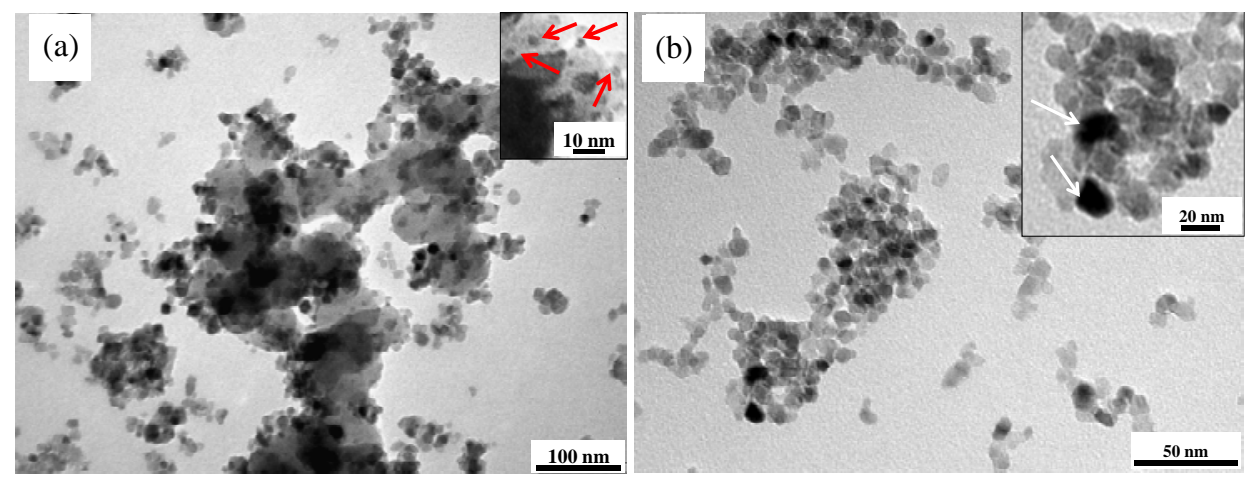

Fig. 3. Selected TEM images of the samples from series S-G5 (a) and S-G16 (b). The arrows indicate the presence of the gold nanoparticles. 
of S-G5 they are situated in the pores). In other words, a semiconductor with its surface covered with Au nanoparticles behaves totally differently compared with the same semiconductor with $\mathrm{Au}$ nanoparticles inside the particle matrix. These relations are important in the analysis of the photocatalytic activity, which is presented later.

\subsection{Photocatalytic performance of the $\mathrm{TiO}_{2}-\mathrm{Au}$ nanomaterials}

As shown in Fig. 4, the most active photocatalyst from the S-G5 series proved to be the sample S-G5-6×, with a degradation rate of $46.4 \times 10^{-3} \mu \mathrm{mol} /(\mathrm{L} \cdot \mathrm{s})$ and $\approx 30 \%$ removal, while the least active was sample S-G5-1×, with a degradation rate of 9.1 $\times 10^{-3} \mu \mathrm{mol} /(\mathrm{L} \cdot \mathrm{s})$ rate, and $20 \%$ salicylic acid removal. The same trend was observed in the S-G16 series. Thus, as Fig. 4 reveals, the most effective catalyst was sample S-16-6× with a degradation rate of $23.2 \times 10^{-3} \mu \mathrm{mol} /(\mathrm{L} \cdot \mathrm{s})$ and $25 \%$ removal, and the least active one was S-G16-1× with a degradation rate of $6.5 \times 10^{-3} \mu \mathrm{mol} /(\mathrm{L} \cdot \mathrm{s})$ rate and $13 \%$ removal. All of the reaction rates and degradation efficiencies are presented in Table 1. P25 was also tested under similar conditions, and the obtained reaction rate was $6.1 \times 10^{-3} \mu \mathrm{mol} /(\mathrm{L} \cdot \mathrm{s})$ with $8 \%$ salicylic acid removal.

Summarizing the results presented above, one can conclude that the photocatalytic efficiency increased as the concentration of gold nanoparticles increased. Furthermore, if we estimate the ratio of the reaction rates for the best/worst sample in each series, we obtain 5.1 (for series S-G5) and 3.5 (for series S-G16). The less effective enhancement for series S-G16 was probably a result of the "boundary" zone, as shown by Lopez et

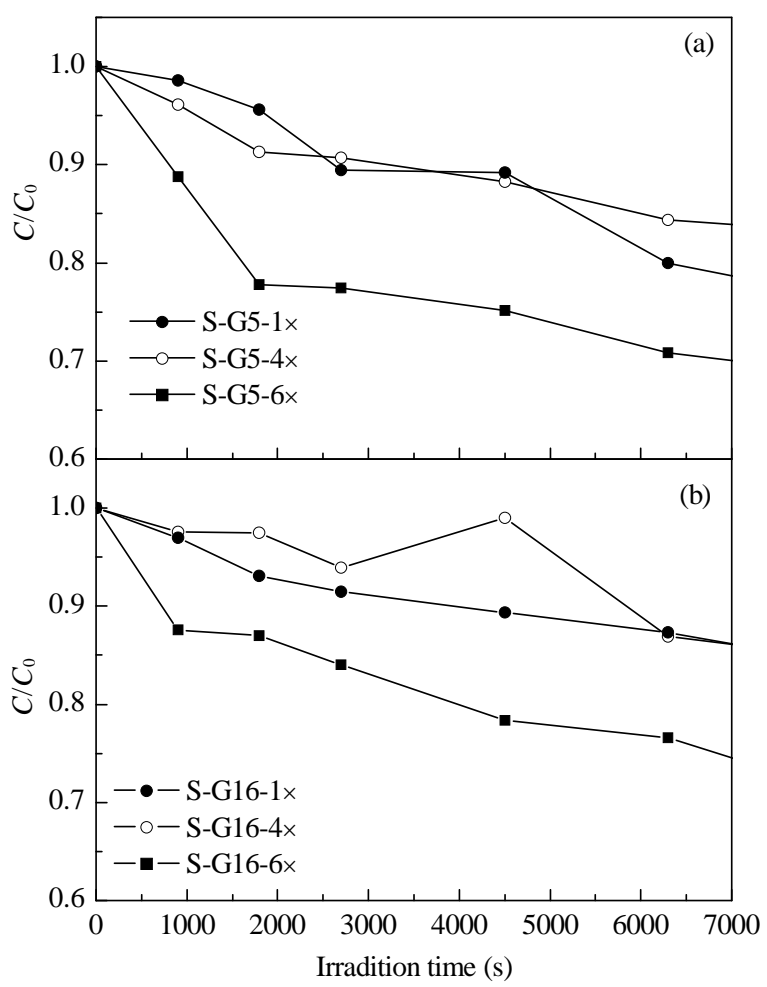

Fig. 4. Salicylic acid degradation curves for the samples containing 5 $\mathrm{nm}$ (a) and $16 \mathrm{~nm}$ (b) gold nanoparticles. al. [44]. This zone also acts as a charged double layer that hinders the electron transfer, which is crucial for noble metal-containing titania $[45,46]$.

In general, when titania aerogels are loaded with gold nanoparticles, the photocatalytic efficiency increases [47]. This is because upon UV irradiation, the photo-generated electrons migrate to the Fermi energy level of the Au nanoparticles. At the same time, the formed Schottky barrier hinders the inverse migration; hence, charge recombination is avoided. The electrons accumulated on the gold clusters or in the conduction band of titania are further transferred to the oxygen absorbed on the surface, and form $\mathrm{O}_{2} \cdot-$ or $\mathrm{O}_{2}{ }^{2-}$. On the other hand, the holes accumulated in the valence band of titania act as hydroxylation agents with aromatic compounds [15,16,47]. As the number of $\mathrm{Au}-\mathrm{TiO}_{2}$ contacts increases, the number of electron-hole pairs generated also increases, which leads to higher photocatalytic activities, as observed in Table 1.

Besides the energetic aspects, in Table 1 we can observe that the samples from series S-G5 had lower specific surface areas compared with the samples from series S-G16. In our recent paper [48], we demonstrated that in noble metal (silver)-deposited titania aerogels, the surface area decreases as the number of crystalline zones increases. The higher crystallinity grade was also found to be responsible for the observed activities [48]. Since the photocatalytic activity of the S-G5 samples was enhanced compared with the S-G16 samples (see Table 1), one can assume that the number of crystalline sites was higher in the S-G5 series.

Another enhancing factor (this is not yet proven experimentally) for the sampleseries S-G5 could have been the presence of the brookite nanoparticles. Their role is not yet entirely clarified in the literature, but several reports can be found in which brookite was proven to be a key factor $[46,49,50]$ in the achieved activity. More precisely, materials containing two kinds of semiconductors or two phases of the same semiconductor show enhanced photocatalytic activity, because of the formation of hetero-junctions. As already mentioned, anatase and brookite were present in the S-G5 series. Considering that the band-gap energies of those two are 3.2 and $2.98 \mathrm{eV}$, respectively, the photo-generated electrons from the anatase phase can easily migrate to the conduction band of brookite. Thus, the recombination of $\mathrm{e}^{-}-\mathrm{h}^{+}$is avoided, and the photocatalytic efficiency is enhanced. A similar situation was observed by $\mathrm{Yu}$ et al. [50] on a $\mathrm{Ag}-\mathrm{TiO}_{2}$ multiphase nano-composite thin film. In addition, some theories say that brookite's role is strongly related to its indirect bandgap [51]. However, caution should be taken, because in our samples the brookite concentration was relatively low $(\approx 10 \%$ from the crystalline mass, amorphous component not calculated).

To the best of our knowledge, the majority of gold-titania catalysts are prepared via the reduction of gold on the titania surface $[46,52]$. This sample preparation procedure results in materials that make the observation of the $\mathrm{Au}-\mathrm{TiO}_{2}$ boundary zone's effect on the photocatalytic activity rather difficult. The above-mentioned observations and results related to the photocatalytic activity of the as-prepared samples could therefore have a significant impact on the future synthesis of catalysts. 


\section{Graphical Abstract}

Chin. J. Catal., 2013, 34: 734-740 doi: 10.1016/S1872-2067(11)60500-7

Behavior of gold nanoparticles in a titania aerogel matrix: Photocatalytic activity assessment and structure investigations

Zsolt PAP, Andreea RADU, Izabella Jolan HIDI, Georgian MELINTE, Lucian DIAMANDESCU, Traian POPESCU, Lucian BAIA, Virginia DANCIU, Monica BAIA*

Babes-Bolyai University, Romania; National Institute of Materials Physics, Romania

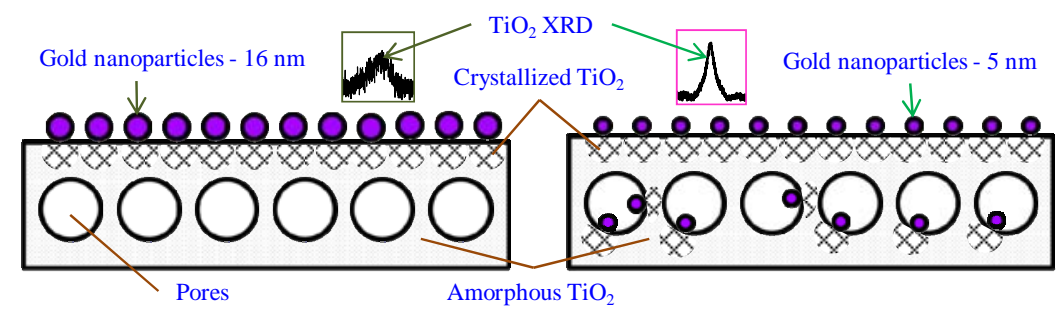

$\mathrm{A} \mathrm{TiO}_{2}-\mathrm{Au}$ aerogel composite was investigated to determine the effects of the presence and size of gold particles on the photocatalytic efficiency of the nanoarchitectures.

\section{Conclusions}

Titania-gold nanomaterials with different amounts of gold nanoparticles of two different average dimensions were successfully synthesized, and were tested for salicylic acid photodegradation under UV light. The obtained materials contained a significant amount of amorphous matter, beside anatase and brookite crystalline phases (the latter was only detected in the case of samples in the S-G5 series). The effects of gold on the crystallization process were twofold. The presence of the noble metal nanoparticles resulted in a multiplication of the number of crystallized zones, and the smaller gold particles enabled a more extended crystallization, as demonstrated by the diffraction patterns of the photocatalysts. The morpho-structural parameters were found to be directly related to the photocatalytic performances; high activity values were achieved compared with a bare titania aerogel.

\section{References}

[1] Petrick G, Schulz-Bull D E, Martens V, Scholz K, Duinker J C. Marine Chem, 1996, 54: 369

[2] Schulz-Bull D E, Petrick G, Bruhn R, Duinker J C. Marine Chem, 1998, 61: 101

[3] Molinari R, Palmisano L, Drioli E, Schiavello M. J Membr Sci, 2002, 206: 399

[4] Martin R J, Iwugo G, Pawlowski L. Physicochemical Methods for Water and Wastewater Treatment. New York: Elsevier, 1989. 265

[5] Le-Clech P, Lee E-K, Chen V. Water Res, 2006, 40: 323

[6] Baia M, Melinte G, Barbu-Tudoran L, Diamandescu L, Iancu V, Cosoveanu V, Danciu V, Baia L. J Phys: Conference Series, 2011, 304: 012059/1

[7] Bao L J, Maruya K A, Snyder S A, Zeng E Y. Environ Pollut, 2012, 163: 100

[8] Barba-Brioso C, Fernandez-Caliani J C, Miras A, Cornejo J, Galan E. Mar Pollut Bull, 2010, 60: 1259

[9] Ma J Z, Ding Z Y, Wei G X, Zhao H, Huang T M. J Environ Manage,
2009, 90: 1168

[10] Kumar C S S R. Nanomaterials for Life Science. Vol. 8. Weinheim: Wiley, 2010.149

[11] Zhang L D, Fang M. Nano Today, 2010, 5: 128

[12] Sharma B, Frontiera R R, Henry A-I, Ringe E, Van Duyne R P. Mater Today, 2012, 15: 16

[13] Fujishima A, Zhang X T, Tryk D A. Surf Sci Rep, 2008, 63: 515

[14] Hashimoto K, Irie H, Fujishima A. Jpn J Appl Phys, 2005, 44: 8269

[15] Vione D, Picatonotto T, Cartotti M E. J Cosmet Sci, 2003, 54: 513

[16] Xiang Q J, Yu J G, Wong P K. J Colloid Interface Sci, 2011, 357: 163

[17] Kamat P V.J Phys Chem B, 2002, 106: 7729

[18] Subramanian V, Wolf E E, Kamat P V. J Am Chem Soc, 2004, 126: 4943

[19] Danciu V, Peter A. $\mathrm{TiO}_{2}$ Aerogels Based Applications to Environmental Remediation. Cluj-Napoca: Risoprint, 2010

[20] Yu K F, Tian Y, Tatsuma T. Phys Chem Chem Phys, 2006, 8: 5417

[21] Martin S T, Herrmann H, Hoffmann M R.J Chem Soc, Faraday Trans, 1994, 90: 3323

[22] Linsebigler A L, Lu G Q, Yates J T. Chem Rev, 1995, 95: 735

[23] Tian Y, Tatsuma T. J Am Chem Soc, 2005, 127: 7632

[24] Du L, Furube A, Hara K, Katoh R, Tachiya M. Proc SPIE, 2007, 6831: 68310W-1

[25] Sonawane R S, Dongare M K. J Mol Catal A, 2006, 243: 68

[26] Popa M, Diamandescu L, Vasiliu F, Teodorescu C M, Cosoveanu V, Baia M, Feder M, Baia L, Danciu V. J Mater Sci, 2009, 44: 358

[27] Huesing N, Schubert U. Angew Chem, Int Ed, 1998, 37: 22

[28] Zhu Z, Tsung L Y, Tomkiewicz M. J Phys Chem, 1995, 99: 15945

[29] Baia L, Peter A, Cosoveanu V, Indrea E, Baia M, Popp J, Danciu V. Thin Solid Films, 2006, 511-512: 512

[30] Georgescu D, Roiban L, Ersen O, Ihiawakrim D, Baia L, Simon S. RSC Adv, 2012, 2: 5358

[31] Murdoch M, Waterhouse G I N, Nadeem M A, Metson J B, Keane M A, Howe R F, Llorca J, Idriss H. Nat Chem, 2011, 3: 489

[32] Chiarello G L, Forni L, Selli E. Catal Today, 2009, 144: 69

[33] Peter A, Baia M, Toderas F, Lazar M, Tudoran L B, Danciu V. Stud Univ Babes-Bolyai, 2009, 3: 161

[34] Turkevich J, Stevenson P C, Hillier J. Discuss Faraday Soc, 1951, 11: 55

[35] Brust M, Walker M, Bethell D, Schiffrin D J, Whyman R. J Chem Soc, 
Chem Commun, 1994: 801

[36] Young R A. The Rietveld Method. Oxford: Oxford University Press, 1993

[37] Nobbs J H. Rev Prog Color Relat Top, 1985, 15: 66

[38] Murphy A B. Sol Energy Mater Sol Cells, 2007, 91: 1326

[39] Silva T R, Valdman E, Valdman B, Leite S G F. Braz J Microbiol, 2007, 38: 39

[40] Pap Zs, Karácsonyi É, Cegléd Zs, Dombi A, Danciu V, Popescu I C, Baia L, Oszkó A,Mogyorósi K. Appl Catal B, 2012, 111-112: 595

[41] Philip D. Spectrochim Acta Part A, 2008, 71: 80

[42] Basu S, Ghosh S K, Kundu S, Panigrahi S, Praharaj S, Pande S, Jana S, Pal S. J Colloid Interface Sci, 2007, 313: 724

[43] Markov I V. Crystal Growth for Beginners: Fundamentals of Nucleation, Crystal Growth and Epithaxy. 2nd Ed. Singapore: World
Scientific Publishing Co Pte Ltd, 2003. 445

[44] Lopez N, Nørskov J K. Surf Sci, 2002, 515: 175

[45] Hirakawa T, Kamat P V. J Am Chem Soc, 2005, 127: 3928

[46] Ismail A A, Kandiel T A, Bahnemann D W. J Photochem Photobiol A, 2010, 216: 183

[47] Yu J G, Yue L, Liu S W, Huang B B, Zhang X Y. J Colloid Interface Sci, 2009, 334: 58

[48] Georgescu D, Pap Zs, Baia M, Fort C I, Danciu V, Melinte G, Baia L, Simon S. Stud Univ Babes-Bolyai Chem, 2011, 3: 51

[49] Hao H Y, Zhang J L. Mater Lett, 2009, 63: 106

[50] Yu J G, Xiong J F, Cheng B, Liu S W. Appl Catal B, 2005, 60: 211

[51] Zallen R, Moret M P. Solid State Commun, 2006, 137: 154

[52] Maicu M, Hidalgo M C, Colon G, Navio J A.J Photochem Photobiol A, 2011, 217: 275 